\title{
FATORES EXTRÍNSECOS E INTRÍNSECOS DA ESTRATÉGIA DE EXPATRIAÇÃO - UMA PROPOSTA DE FRAMEWORK PARA AS SUBSIDIÁRIAS ESTRANGEIRAS
}

\section{RESUMO}

A estratégia de expatriação trata da decisão de designação de pessoas para atender às demandas internacionais das empresas multinacionais (EMNs). O estudo visou responder à questão: Quais são as estratégias relacionadas aos fatores intrínsecos e extrínsecos determinantes da decisão de expatriação das empresas multinacionais japonesas? Teve o objetivo de analisar as estratégias relacionadas aos fatores intrínsecos e extrínsecos da decisão de expatriação. Tratou-se de estudo quantitativo dos dados secundários de investimentos estrangeiros japoneses publicados pela Toyo Keizai. Foram analisadas 107 subsidiárias de multinacionais japonesas na América Latina, de 2006 a 2012, por meio de regressão múltipla com dados em painel. Propôs-se framework da estratégia de expatriação. Concluiu-se que distância cultural, dissimilaridade institucional e controle operacional determinam a estratégia de expatriação das operações internacionais.

Palavras-chaves: Estratégia de Expatriação; Fatores Organizacionais; Fatores Ambientais.

\section{INTRINSIC AND EXTRINSIC FACTORS OF EXPATRIATION STRATEGY - A PROPOSED FRAMEWORK FOR FOREIGN SUBSIDIARIES}

\begin{abstract}
The expatriation strategy is related to the decision to assign people to meet the international demands of multinational companies (MNCs). The study aimed at answering the question: What are the strategies related to intrinsic and extrinsic factors determining the decision of expatriation of Japanese multinational companies? It had the objective to analyze the intrinsic and extrinsic factors of the decision of expatriation. This was a quantitative study with secondary data of Japanese foreign investment published by Toyo Keizai. A total of 107 subsidiaries of Japanese multinationals were analyzed in Latin America, 2006-2012, through multiple regression with panel data. It was proposed an expatriation strategy framework. The conclusion was that cultural distance, institutional and operational control dissimilarity determine the strategy for expatriation of international operations.
\end{abstract}

Keywords: Expatriation Strategy; Organizational Factors; Environmental Factors. 
Fatores Extrínsecos e Intrínsecos da Estratégia de Expatriação - uma Proposta de Framework para as Subsidiárias Estrangeiras

\section{FACTORES EXTRÍNSECOS E INTRÍNSECOS EXPATRIACIÓN DE ESTRATEGIA - UN MARCO PROPUESTO PARA FILIALES EXTRANJERAS}

\section{RESUMEN}

La Estrategia de expatriación con la decisión de asignación de personas para cumplir con las demandas internacionales de las empresas multinacionales (EMN). El estudio tuvo como objetivo responder a la pregunta: ¿Cuáles son las estrategias relacionadas con la determinación de factores intrínsecos y extrínsecos de decisión expatriación de empresas multinacionales japonesas? Tuvo como objetivo analizar las estrategias relacionadas con factores intrínsecos y extrínsecos de decisión expatriación. Este fue un estudio cuantitativo de los datos secundarios de la inversión extranjera japonesa Toyo Keizai publicados por. 107 filiales de multinacionales japonesas fueron analizados en América Latina, 2006-2012, por medio de regresión múltiple con datos de panel. Se propuso marco de la estrategia de la expatriación. Se concluyó que la distancia cultural, control institucional y operativa disimilitud determinan la estrategia de expatriación de las operaciones internacionales.

Palabras clave: Estrategia Expatriación; Los factores organizativos; Factores ambientales.

Márcia Zabdiele Moreira ${ }^{1}$ Mário Henrique Ogasavara ${ }^{2}$ Elano Ferreira Arruda ${ }^{3}$

\footnotetext{
${ }^{1}$ Doutora em Administração de Empresas pela Universidade de Fortaleza - UNIFOR. Professora da Universidade da Integração Internacional da Lusofonia Afro-Brasileira - UNILAB. Brasil. E-mail: marciazabdiele@gmail.com

${ }^{2}$ Doutor em Administração pela University of Tsukuba, Japão. Professor da Escola Superior de Propaganda e Marketing - ESPM.. Brasil. E-mail: mario.ogasavara@espm.br

${ }^{3}$ Doutor em Economia pela Universidade Federal do Ceará - UFC. Brasil. E-mail: elanocaen@ gmail.com
} 
Fatores Extrínsecos e Intrínsecos da Estratégia de Expatriação - uma Proposta de Framework para as Subsidiárias Estrangeiras

\section{INTRODUÇÃO}

Empresas Multinacionais (EMNs) são organizações que tipicamente são formadas por uma matriz (parent firm) e uma ou mais subsidiárias dispersas geograficamente. Possuem parceiros locais nos países hospedeiros para serem seus suportes e contribuírem na sua atuação em mercados estrangeiros (GREWAL et al., 2013).

Faro e Faro (2007) explicam que a globalização de mercados possibilitou a redução das barreiras comerciais e o desenvolvimento de diversos acordos internacionais entre países resultando, inclusive, no surgimento e formação de blocos econômicos. Este contexto favorável possibilitou que as EMNs pudessem intensificar o ingresso em outros países em busca de novos mercados.

A expansão das EMNs no mercado internacional está relacionada ao envolvimento das pessoas de nível estratégico da organização. Desse modo, no processo de internacionalização é preciso determinar como é realizada a designação de pessoas para os cargos de gestão das novas subsidiárias que estão sendo instaladas em outros países.

A estratégia de expatriação está relacionada à decisão de designação de pessoas para atender às demandas internacionais da empresa e envolve elementos como: custo da expatriação para a empresa e para o expatriado, ajustamento intercultural do expatriado, definição de como a empresa pretende exercer $o$ controle da subsidiária estrangeira, transferência de conhecimento da matriz para a subsidiária, distância e aspectos institucionais, distância e aspectos culturais.

Foram identificados na literatura gaps que o presente estudo pretendeu suprir. São eles: o termo 'Estratégia de Expatriação' ainda é incipiente na literatura; boa parte dos estudos realizou apenas estudos transversais (um único período) relacionando expatriação e demais teorias; há uma falta de estudos especificamente na América Latina; quando utilizado a base de dados de subsidiárias japonesas publicada pela Toyo Keizai, o ano mais recente analisado foi de 2008; há pouca evidência empírica para identificar como os níveis da gestão de expatriação são determinados nas subsidiárias das EMNs.

Esse estudo tem o intuito de contribuir e desenvolver o tema Estratégia de Expatriação. Adicionalmente, esta pesquisa tem sua relevância e diferencial de ser realizado por meio de análise quantitativa com dados em painel, pois a natureza abrangente e longitudinal dos dados permite uma perspectiva dinâmica e uma análise evolutiva das subsidiárias estrangeiras, possibilitando assim uma capacidade única para resolver as questões complexas que foram levantadas nesse estudo.
Percebe-se ainda, que o uso de expatriados é um elemento fundamental para a estratégia internacional das EMNs (BEAMISH; INKPEN, 1998). Desse modo, considerando as lacunas teórico-empíricas do tema e a relevância do expatriado na estratégia internacional das organizações, o estudo visou responder à seguinte questão de pesquisa: Quais são as estratégias relacionadas aos fatores intrínsecos e extrínsecos determinantes da decisão de expatriação das empresas multinacionais japonesas?

Teve-se o objetivo de identificar os fatores intrínsecos e extrínsecos relacionados à expatriação e por meio disso propor um framework da estratégia de expatriação das empresas multinacionais.

Para atingir o objetivo do estudo, a metodologia deste trabalho, inicialmente consistiu em um levantamento bibliográfico sobre as temáticas: designação internacional, gestão de expatriação. Notase que foi encontrada uma literatura extensa sobre essas áreas, entretanto há uma escassez de estudos sobre uma teoria que explique a Estratégia de Expatriação. Embora a literatura tenha avançado no aspecto teórico sobre a relação entre a estratégia competitiva das multinacionais e sua gestão de recursos humanos internacionais (GIRH), poucos estudos têm procurado testar empiricamente a questão de como imperativos estratégicos afetam as decisões dos gestores de recursos humanos da filial estrangeira (PAIK; ANDO, 2011).

Com o desenvolvimento e teste empírico das hipóteses no estudo propôs-se a elaboração de um framework inicial relacionando os determinantes intrínsecos e extrínsecos da estratégia de expatriação. Após o teste das hipóteses, compôs-se framework final.

A base de dados da Toyo Keizai foi utilizada como fonte principal de informações sobre fatores intrínsecos relacionados às práticas de gestão das empresas multinacionais japonesas (conhecimento experiencial e controle organizacional). Entretanto, para melhor compreensão das variáveis extrínsecas como aspectos institucionais (distância cultural e institucional) que caracterizam as especificidades dos países, foram utilizadas as bases de dados do Global Competitiveness Report (GCR) e do Worldwide Governance Indicator (WGI).

Realizou-se regressão múltipla dos dados em painel no período de 2006 a 2012, com as subsidiárias estrangeiras das empresas multinacionais japonesas instaladas na América Latina. Para selecionar o modelo de regressão mais adequado, utilizou-se o teste de Hausman para escolher entre o modelo de Efeitos Fixos e o Modelo de Efeitos Aleatórios. Adicionalmente, aplicou-se um teste de heterocedasticidade, de modo a estimar um modelo com correção para esse problema.

A estrutura do artigo foi composta pelos seguintes elementos: a primeira seção consistiu na 
introdução com a apresentação das pretensões do estudo. Na segunda seção abordou a revisão de literatura bem como o desenvolvimento das hipóteses relacionadas aos fatores determinantes da expatriação, tanto nos aspectos intrínsecos como extrínsecos. Em seguida é apresentado o método utilizado para a realização da pesquisa. A quarta seção consiste na apresentação das discussões e resultados da pesquisa. Finalmente, a última seção discute as considerações finais bem como as limitações e direcionamentos para futuras pesquisas.

\section{REFERENCIAL TEÓRICO}

Para compreender os fatores determinantes das empresas multinacionais em expatriarem funcionários para gerenciar as subsidiárias estrangeiras, o estudo concentrou-se em analisar as empresas multinacionais e seus desafios de designação de pessoal para gestão das subsidiárias estrangeiras, os quais estão relacionados ao seu ambiente interno e externo.

No nível organizacional (fatores intrínsecos) foram analisados o controle organizacional e o conhecimento experiencial da subsidiária estrangeira. No que se refere ao ambiente externo (fatores extrínsecos) foram estudadas a distância cultural e diferenças institucionais entre os países. Também foram analisadas variáveis de controle.

\subsection{Fatores Intrínsecos da Expatriação}

A designação de pessoas para as subsidiárias estrangeiras envolve uma combinação de gestores do país de origem da matriz e do país hospedeiro. Também reflete a orientação das empresas multinacionais em direção ao controle e coordenação, à transferência de conhecimento e aprendizagem e às questões estratégicas (DELIOS; BJORKMAN, 2000; HARZING, 2001).

Os fatores intrínsecos às empresas multinacionais que na literatura têm sido considerados determinantes para a estratégia de expatriação são: (a) controle organizacional (b) conhecimento experiencial. O nível de controle sobre as subsidiárias estrangeiras é um assunto importante na pesquisa sobre empresas multinacionais (XU; PAN; BEAMISH, 2004).

Em contrapartida, Gomez e Sanchez (2005) explanam que há uma escassez de pesquisas sobre os fatores determinantes das escolhas dos mecanismos de controle possíveis para as empresas multinacionais, apesar de esses mecanismos serem cruciais para o processo de implementação estratégica.

Em relação às áreas de foco do controle organizacional, as empresas têm direcionado principalmente para setores como: marketing, vendas, distribuição, gestão e operações gerais, finanças e contabilidade, pesquisa e desenvolvimento, produção e qualidade, e recursos humanos (LE, 2009). Além disso, Ogasavara (2012) indica que o controle da empresa matriz sobre as subsidiárias têm sido relacionado à estabilidade do negócio, apesar de não se ter definido claramente a direção desse efeito.

Nesse estudo o controle foi analisado por meio dos três instrumentos propostos por Singh (2012). Com o intuito de testar essas teorias relacionando-as à expatriação de funcionários, as variáveis de controle foram classificadas da seguinte forma:

(a) controle acionário da matriz;

(b) controle operacional da matriz;

(c) controle por meio do modo de entrada no mercado internacional.

De acordo com Jaussaud e Schaaper (2006), há uma diversidade de instrumentos que as multinacionais podem usar para controlar suas subsidiárias. Desse modo, Martinez e Jarillo (1989) sugerem que a combinação de vários instrumentos, de acordo com o contexto, deve ser a chave do sucesso, pois o controle da subsidiária estrangeira é um fenômeno complexo e multidimensional.

\subsection{Controle Acionário da Matriz}

A escolha dos níveis de controle acionário nas subsidiárias estrangeiras é um tópico central da pesquisa em gestão internacional devido às implicações estratégicas relacionadas ao controle e à performance das subsidiárias (PENG, 2012).

Dois tipos de controle têm sido extensivamente discutidos na literatura: controle estratégico comumente associado com o controle acionário e o controle operacional por meio do uso de expatriados do país de origem. A hipótese de que quanto maior o investimento nas novas subsidiárias japonesas, maior a proporção de expatriados designados, foi testada por Widmier, Brouthers e Beamish (2008). Contudo, a hipótese foi rejeitada empiricamente. Os autores não constataram relação direta entre as variáveis.

Delios e Bjorkman (2000) também testaram a hipótese de que há uma relação positiva entre o uso de expatriados e controle acionário, contudo, obtiveram resultado diferente a confirmarem-na empiricamente. Os autores complementaram a análise ao testar também a hipótese de que a relação positiva entre controle acionário e o uso de expatriados é mais forte para subsidiárias localizadas nos Estados Unidos do que na China. Contudo, os autores constataram apenas um suporte parcial sobre a hipótese, demonstrando pouca evidência empírica e relação entre as variáveis.

Widmier, Brouthers e Beamish (2008) explicam que quanto maior o investimento em subsidiárias estrangeiras, maior o risco da matriz. E esse risco maior conduz a níveis mais altos de falta de supervisão do país de origem. Um método de prover maior supervisão é por meio do uso de gestores expatriados (O’DONNELL, 2000). 
Fatores Extrínsecos e Intrínsecos da Estratégia de Expatriação - uma Proposta de Framework para as Subsidiárias Estrangeiras

Os resultados contrários das pesquisas de Widmier, Brouthers e Beamish (2008) e Delios e Bjorkman (2000) comprovam que não está consolidado na literatura se os expatriados podem controlar melhor os investimentos feitos pela matriz no mercado internacional e verificar se estes estão sendo bem empregados do que os gestores do país hospedeiro. Não se inferiu ainda se há uma relação direta ou inversa entre o crescimento de investimentos no país hospedeiro e a designação de gestores locais do país hospedeiro ou de expatriado.

É provável que as empresas multinacionais busquem minimizar o risco dos investimentos realizados no mercado internacional por meio do controle operacional de um expatriado. Contudo, faz-se necessário a realização de novos testes para verificar a relação entre participação acionária (controle acionário) da empresa matriz sobre as subsidiárias estrangeiras e o uso de expatriação. Com isso, propôsse a hipótese H1a:

H1a - Há uma relação direta entre a participação acionária da matriz (controle acionário) e a designação de expatriados da empresa multinacional para gerenciar a subsidiária estrangeira.

\subsection{Controle Operacional da Matriz}

As empresas multinacionais têm quantidades variadas de expatriados nas subsidiárias estrangeiras. E apesar dessas duas funções principais que os expatriados realizam, ainda não constatou empiricamente se há uma relação direta ou inversa entre a quantidade de expatriados e a nacionalidade do diretor da subsidiária.

Além do controle acionário, as empresas multinacionais também podem controlar suas unidades estrangeiras por meio da designação de expatriados. A expatriação não é somente um elemento importante de governança da subsidiária, mas também tem importantes implicações na performance e desenvolvimento de capacidades (HARZING, 2001).

Widmier, Brouthers e Beamish (2008) argumentam que quando as firmas estão criando novas subsidiárias em mercados estrangeiros enfrentam muitas decisões relacionadas a seus recursos humanos. Uma das decisões mais básicas tem grandes implicações na eficiência e lucratividade da subsidiária e refere-se à taxa de pessoal expatriado em relação aos empregados locais.

De acordo com Delios e Bjorkman (2000), os expatriados desempenham principalmente dois papéis nas subsidiárias estrangeiras. O primeiro é uma função de controle na qual o expatriado trabalha para alinhar as operações da unidade estrangeira com as da matriz.

$\mathrm{O}$ segundo é uma função relacionada ao conhecimento. Nesse papel, o expatriado age tanto para transferir conhecimento da matriz para a subsidiária quanto para ser um agente de aquisição de conhecimento do país hospedeiro e difusor entre as demais unidades.

As empresas multinacionais têm quantidades variadas de expatriados nas subsidiárias estrangeiras. E apesar dessas duas funções principais que os expatriados realizam, ainda não se constatou empiricamente se há uma relação direta ou inversa entre a quantidade de expatriados e a nacionalidade do Diretor da subsidiária.

Faz-se necessário, portanto, compreender se o controle operacional por meio de expatriados aumenta quando o Chief Executive Officer (CEO) é um gestor expatriado e se a permanência do CEO na gestão da subsidiária estrangeira também influencia o uso da expatriação. Nota-se que essas hipóteses não foram testadas anteriormente por outros pesquisadores. Contudo, a literatura tem indicado a importância dos expatriados no controle operacional das subsidiárias estrangeiras. Diante disso, propõem-se as hipóteses H1b e H1c:

H1b - Há uma relação direta entre expatriação e a nacionalidade do CEO da subsidiária, particularmente se esta for a mesma do país de origem da empresa matriz estrangeira.

H1c - Há uma relação inversa entre expatriação e a permanência do mesmo CEO na gestão das subsidiárias estrangeiras.

\subsection{Modo de Entrada no Mercado Internacional}

Por mais que as empresas multinacionais tenham criado mais subsidiárias de controle integral do que subsidiárias que são joint ventures desde o começo dos anos 1990 (JAUSSAUD; SCHAAPER; ZHANG, 2001), a questão do controle de suas atividades no mercado internacional continua sendo um assunto crucial.

Acrescentam Geringer e Hebert (1989) que os mecanismos de controle são arranjos estruturais desenvolvidos para determinar e influenciar o que os membros da organização fazem. Nas joint ventures, por ter duas ou mais partes envolvidas, o controle organizacional é complexo. Conforme explanação de Calantone e Zhao (2001) quando as empresas multinacionais estão familiarizadas com a cultura e ambiente locais, elas podem exercer controle considerável sobre as joint venture internacionais e além disso, obter conhecimento local.

Abdellatif, Amann e Jaussaud (2010) explicam que estabelecer subsidiárias em mercados desconhecidos é difícil e arriscado. Firmas podem estabelecer uma joint venture com um parceiro local para se beneficiarem de sua experiência no mercado local e a habilidade de acessar vários recursos, como acesso aos distribuidores e fornecedores locais, 
recursos humanos. Contudo, subsidiárias de controle integral são mais fáceis de controlar e o processo de tomada de decisão é mais fácil porque não requer confirmação constante com parceiros locais.

Segundo Kogut (1988), quando as empresas multinacionais têm suficiente experiência em um país, elas devem confiar mais em subsidiárias de controle integral ao invés de joint ventures. Em contraste, firmas confiam mais em joint ventures quando o nível de risco aumenta, pois envolver um parceiro local por meio de uma joint venture pode ajudar a firma a gerenciar alto nível de risco dos países.

Os questionamentos que surgem em relação ao modo de entrada no mercado internacional referem-se à contribuição do expatriado relacionada ao controle acionário da multinacional.

Schotter e Beamish (2011) constataram que a probabilidade da MNE designar funcionários locais como gestores da subsidiária estrangeira é maior em subsidiárias que são joint ventures, comparado às subsidiárias de controle integral (Wholly Owned Subsidiary - WOS). Poucos estudos empíricos foram realizados para se analisar a relação entre as variáveis. Há, portanto, necessidade de se realizar mais pesquisa para se compreender como se a multinacional exerce controle por meio de expatriação mais fortemente em subsidiárias que são joint venture ou subsidiárias integrais. Desse modo, propôs-se a hipótese H1d:

H1d - Há uma relação direta entre o modo de entrada no país hospedeiro por meio de subsidiária de controle integral (WOS) e a designação de expatriados da empresa multinacional para gerenciar a subsidiária estrangeira.

\subsection{Conhecimento Experiencial}

Os expatriados desempenham um papel fundamental na integração da empresa facilitando não apenas a criação de conhecimento nas subsidiárias para ser utilizado por outros gestores na rede de relacionamentos, mas também por meio da absorção de conhecimento necessário para todo o resto da network, conforme (GUPTA; GOVINDARAJAN, 1991).

Contudo, há controvérsias no estudo da relação entre conhecimento experiencial e designação de pessoal para subsidiárias estrangeiras. Delios e Bjorkman (2000) explicam que as empresas multinacionais com limitada experiência no país hospedeiro tendem a realizar investimentos no desenvolvimento de conhecimento da empresa matriz sobre as condições locais do país hospedeiro por meio do uso de expatriados.

Em contrapartida, os autores também afirmam que se poderia argumentar o contrário, que as empresas multinacionais com escasso conhecimento sobre o país hospedeiro designariam menos expatriados, pois estes estariam correndo mais risco de ter uma performance deficiente ao atuar em um ambiente novo e desconhecido.

Expatriados podem servir como mecanismos de transferência de conhecimento e experiência das empresas multinacionais e serem utilizados para aumentar a eficiência e a competitividade de uma nova subsidiária estrangeira. Além disso, as empresas-mãe experientes se tornam mais adeptas na designação de expatriados para suprirem suas filiais locais com conhecimento e informação, o que lhes permite aumentar a competitividade da subsidiária estrangeira (DOWNES; THOMAS, 2000).

Em contrate, empresas multinacionais com substancial experiência no país hospedeiro das subsidiárias estrangeiras podem ter menos necessidade de designar expatriados. Isso pode ocorrer devido à abundância de gestores experientes com as questões específicas do país hospedeiro juntamente com uma compreensão clara das condições de negócios do país hospedeiro permite que as empresas confiem pesadamente em treinamento e designação de gestores locais (HARVEY; NOVICEVIC, 2000).

Gong (2003), Tan e Mahoney (2006), Wilkinson et al. (2008), Xu, Pan e Beamish (2004) e Ando e Paik (2013), contudo, encontraram resultado contrário ao de Widmier, Brouthers e Beamish (2008) e Delios e Bjorkman (2000). Houve maior incidência de confirmação de relação inversa do que relação direta entre as variáveis. Assim, para esse estudo, decidiu-se testar a existência de relação inversa entre as variáveis.

A hipótese $\mathrm{H} 2$ relaciona a decisão de expatriação da empresa com a experiência da matriz no país hospedeiro. Desse modo, considerando o papel estratégico do expatriado na criação e difusão de conhecimento experiencial para as empresas multinacionais propôs-se:

H2 - Há uma relação inversa entre conhecimento experiencial da empresa matriz no país hospedeiro e a designação de expatriados da empresa multinacional para gerenciar a subsidiária estrangeira.

Após desenvolver os fatores intrínsecos, o próximo tópico abordará os aspectos extrínsecos relacionados à expatriação.

\subsection{Fatores Extrínsecos da Expatriação}

O ambiente internacional é formado por elementos que impactam as decisões e a atuação das empresas multinacionais como os aspectos relacionados aos seguintes escopos: político, econômico, mercadológico, inovação, preparo tecnológico, saúde, custo de vida, mercado de trabalho, o mercado financeiro, social, cultural, educacional e infraestrutura dos países.

Neste estudo, foram analisados os fatores extrínsecos às empresas multinacionais os quais têm 
Fatores Extrínsecos e Intrínsecos da Estratégia de Expatriação - uma Proposta de Framework para as Subsidiárias Estrangeiras

sido considerados determinantes para a estratégia de expatriação: (a) os aspectos institucionais; (b) e a distância cultural.

Consequentemente, a internacionalização das empresas é permeada por uma série de desafios associados ao ambiente internacional e pelo fato da empresa ser estrangeira. Esses elementos desafiadores incluem aspectos como: falta de familiaridade com a cultura do país hospedeiro, o idioma, a política, as regulamentações e outros aspectos institucionais (COOKE, 2012).

\subsection{Aspecto Institucional}

As diferenças institucionais dos países têm chamado a atenção dos pesquisadores, pois essas diferenças influenciam significativamente as decisões estratégicas. A dissimilaridade institucional entre países hospedeiros e o país de origem da matriz apresenta desafios para as multinacionais quando buscam legitimidade no contexto institucional local (KOSTOVA; ZAHEER, 1999; XU; SHENKAR, 2002).

Analogamente, Hilmersson e Janssens (2012) explicam que diferenças entre os ambientes de mercado e as consequências dessas diferenças constituem os principais obstáculos no processo de internacionalização. Um nível elevado de distância psíquica é apresentado como o principal fator que causa incerteza para a empresa e, portanto, tem ocupado um papel central na teoria do processo de internacionalização.

Na perspectiva de Hymer (1960) as diferenças entre o ambiente do país hospedeiro e do país de origem causam o que é chamado de liability of foreingness que se refere à desvantagem dos estrangeiros em realizarem negócios em países hospedeiros, as quais se baseiam em três fatores:

a) risco cambial de operar em um mercado estrangeiro;

b) discriminação das autoridades locais contra as empresas entrantes;

c) desconhecimento das empresas sobre o mercado estrangeiro.

No que se refere aos aspectos institucionais, $\mathrm{Xu}$, Pan e Beamish (2004) confirmaram empiricamente em seu estudo que a MNE manterá menos expatriados na subsidiária estrangeira em que:

a) a distância regulativa for maior; e

b) a distância normativa for maior.

Para os autores, a distância institucional está associada negativamente com a proporção de expatriados. Entretanto, Gaur, Delios e Singh (2007) enfatizaram a importância do controle e transferência de conhecimento sob a condição de grande distância institucional, e encontraram uma associação positiva entre a distância institucional e a proporção de Expatriados.

Ando e Endo (2013) constataram empiricamente uma relação inversa entre distância institucional e a proporção de Expatriados na subsidiária estrangeira corroborando com Xu, Pan e Beamish (2004).

Para Xu, Pan e Beamish (2004) a pesquisa sobre as diferenças nas dimensões institucionais entre os países ainda está uma fase de desenvolvimento. Apesar da crescente atenção sobre as instituições, ainda é relativamente desconhecido como as multinacionais designam pessoas para gerirem as subsidiárias estrangeiras e como estas são preparadas para lidar com os desafios causados pela distância institucional, ou seja, a legitimidade, controle e transferência de conhecimentos.

Em relação ao aspecto institucional e o desafio de vencer as dificuldades de ser estrangeiro em outro país (liability of foreigness), propôs-se a hipótese H3:

H3 - Há uma relação inversa entre dissimilaridade institucional entre o país hospedeiro e o país de origem e a designação de expatriados da empresa multinacional para gerenciar subsidiárias estrangeiras.

\subsection{Distância Cultural}

A cultura de um país tem uma influência forte sobre a formação das crenças, valores, pressupostos e cognição dos seus habitantes. Consequentemente, a cultura nacional afeta significantemente as atitudes e decisões dos gestores (HOFSTEDE, 2001). Conflitos culturais são parte do trabalho diário de um número crescente de funcionários e gestores à medida que as empresas aumentam suas trocas no mercado global, não apenas de produtos, mas também de força de trabalho e de conhecimento (GERTSEN; SODERBERG, 2010).

Hofstede (1980) verificou que as diferenças culturais entre os países referem-se a quatro dimensões: evitar a incerteza; individualismo; tolerância a distância do poder; masculinidade/feminilidade. Posteriormente o autor apresentou a quinta dimensão; orientação a longo prazo versus a curto prazo (HOFSTEDE, 2001). Recentemente, a sexta dimensão foi adicionada: indulgência versus restrição (HOFSTEDE et al., 2010).

Com essas dimensões, o autor criou escalas que contemplam a distância cultural entre os países. Kogut e Singh (1988) explicam que os índices de Hofstede (1980) podem ser criticados por uma série de motivos, principalmente no que se refere à definição das dimensões e a forma de construção da escala. Contudo, também têm características fortes como o tamanho da amostra e sua ênfase em atitudes relacionadas ao ambiente de trabalho. 
A distância cultural da presente pesquisa foi orientada pelas dimensões culturais de Hofstede (1980, 2001) as quais foram aprimoradas com a construção de indicadores para o cálculo da distância cultural entre os países por Kogut e Singh (1988) por meio de uma escala cultural, conforme fórmula apresentada a seguir.

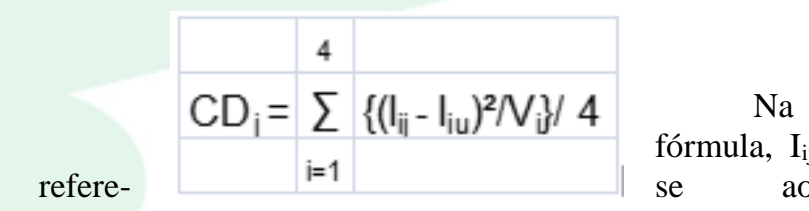
índice "i" da dimensão cultural em relação ao país " $j$ ”. $\mathrm{V}_{\mathrm{i}}$ corresponde à variância do índice da dimensão "i”, "u" indica no caso da fórmula original, os Estados Unidos, mas no caso da presente pesquisa, o Japão. Desse modo, CDj é a diferença cultural do país “j” para o Japão.

Wilkinson et al. (2008) testaram uma hipótese relacionando distância cultural, com controle organizacional e o tempo de atuação da subsidiária estrangeira. Os autores confirmaram empiricamente que a distância cultural tem um impacto mais significante nos mecanismos de controle (como controle acionário e proporção de expatriados) da empresa matriz sobre subsidiárias que são mais novas do que sobre as subsidiárias mais antigas.

Widmier, Brouthers e Beamish (2008) explicam que quanto menor a distância cultural entre o país de origem e o país hospedeiro maior a proporção de expatriados em novas subsidiárias estrangeiras. Para os autores isso pode ser explicado devido aos expatriados entenderem pouco do mercado e da cultura local aumentando as chances de gerarem erros custosos. Isso pode justificar a relação inversa entre distância cultural e proporção de expatriados utilizados pelas empresas multinacionais.

Gong (2003), entretanto, constatou empiricamente que a distância cultural está positivamente relacionada à proporção de expatriados do país de origem da empresa matriz em subsidiárias estrangeiras e a probabilidade de designar, como CEO da subsidiária, um expatriado do país de origem da matriz. Esse resultado contraria a pesquisa de Widmier, Brouthers e Beamish (2008).

Boyacigiller (1990) também identificou em seu estudo que o percentual de expatriados utilizado nas subsidiárias estrangeiras cresce com o aumento da distância cultural, concordando com Gong (2003). Essas contradições alertaram para a necessidade de se realizar mais pesquisas relacionando os temas expatriação e distância cultural e também geraram alguns questionamentos. Assim, propôs-se a hipótese H4:
H4 - Há uma relação inversa entre distância cultural entre o país hospedeiro e o país de origem e a designação de expatriados da empresa multinacional para gerenciar subsidiárias estrangeiras.

\subsection{Tamanho e setor de atuação da empresa multinacional}

As variáveis de controle do estudo foram o tamanho da subsidiária estrangeira e o seu setor de atuação. Nesse item são apresentadas questões referentes à influência dessas variáveis sobre a estratégia de expatriação das empresas multinacionais.

O tamanho da subsidiária pode ser obtido por meio do capital da subsidiária ou por meio do total de empregados. Essas têm sido as formas de análise dessa variável pelos pesquisadores. Widmier, Brouthers e Beamish (2008) testaram por meio do capital, enquanto $\mathrm{Xu}$, Pan e Beamish, 2004, Tan e Mahoney, 2006, Wilkinson et al. (2008) e Ando (2011), por meio da quantidade de empregados da subsidiária.

Tan e Mahoney (2006) realizaram uma pesquisa utilizando a quantidade de empregados como variável de controle do tamanho da subsidiária e constataram que não houve diferença significante do tamanho das subsidiárias estrangeiras em relação à decisão de expatriação das empresas.

Em relação ao capital, Widmier, Brouthers e Beamish (2008) testaram a hipótese de que quanto maior o capital investido pelas multinacionais japonesas em novas subsidiárias maior será a proporção de expatriados. Essa relação positiva entre as variáveis foi confirmada empiricamente. Desse modo, propôs-se a hipótese H5a:

H5a - Há uma relação direta entre o tamanho da subsidiária estrangeira e a designação de expatriados da empresa multinacional para gerenciar subsidiárias estrangeiras.

Ando e Endo (2013) constataram empiricamente que existe uma relação direta e significante entre a intensidade em capital humano e a proporção de PCNs. Os resultados implicam que multinacionais do setor de serviços com grande intensidade em capital humano designam mais PCNs para as subsidiárias estrangeiras.

Tan e Mahoney (2006) testaram a hipótese de que indústrias caracterizadas por um alto nível de customização de produtos reduzem a designação de expatriados para subsidiárias estrangeiras. Contudo, essa hipótese não foi confirmada empiricamente.

A hipótese contrária também foi testada pelos referidos autores, os quais constataram a existência de uma relação direta entre um elevado nível de customização de produtos e a utilização de expatriados em subsidiárias estrangeiras. 
Fatores Extrínsecos e Intrínsecos da Estratégia de Expatriação - uma Proposta de Framework para as Subsidiárias Estrangeiras

Tan e Mahoney (2006) também testaram a hipótese de que em indústrias caracterizadas por um alto nível de incerteza, as EMNs reduzem a utilização de expatriados nas subsidiárias estrangeiras. Testaram ainda a hipótese contrária. Ambas as hipóteses, positiva e negativa, não foram confirmadas empiricamente.

Makino, Beamish e Zhao (2004) constataram que as empresas japonesas investem em setores diferentes dependendo do nível de desenvolvimento dos países. Em se tratando de países desenvolvidos, os japoneses tendem a investir na indústria terciária (não manufatura). Já nos países em desenvolvimento as empresas japonesas têm concentrado seus investimentos em setores da indústria primária e secundária (manufatura).
Destaca-se assim a importância do setor de atuação das empresas multinacionais como fator determinante da decisão de expatriação. Desse modo, propôs-se a hipótese H5b:

$\boldsymbol{H 5 b}$ - Há uma relação direta entre o tipo de indústria e a designação de expatriados da empresa multinacional para gerenciar subsidiárias estrangeiras.

A figura 1 consiste no foco da presente pesquisa e gerou desdobramentos com a apresentação das hipóteses que geraram o framework inicial.

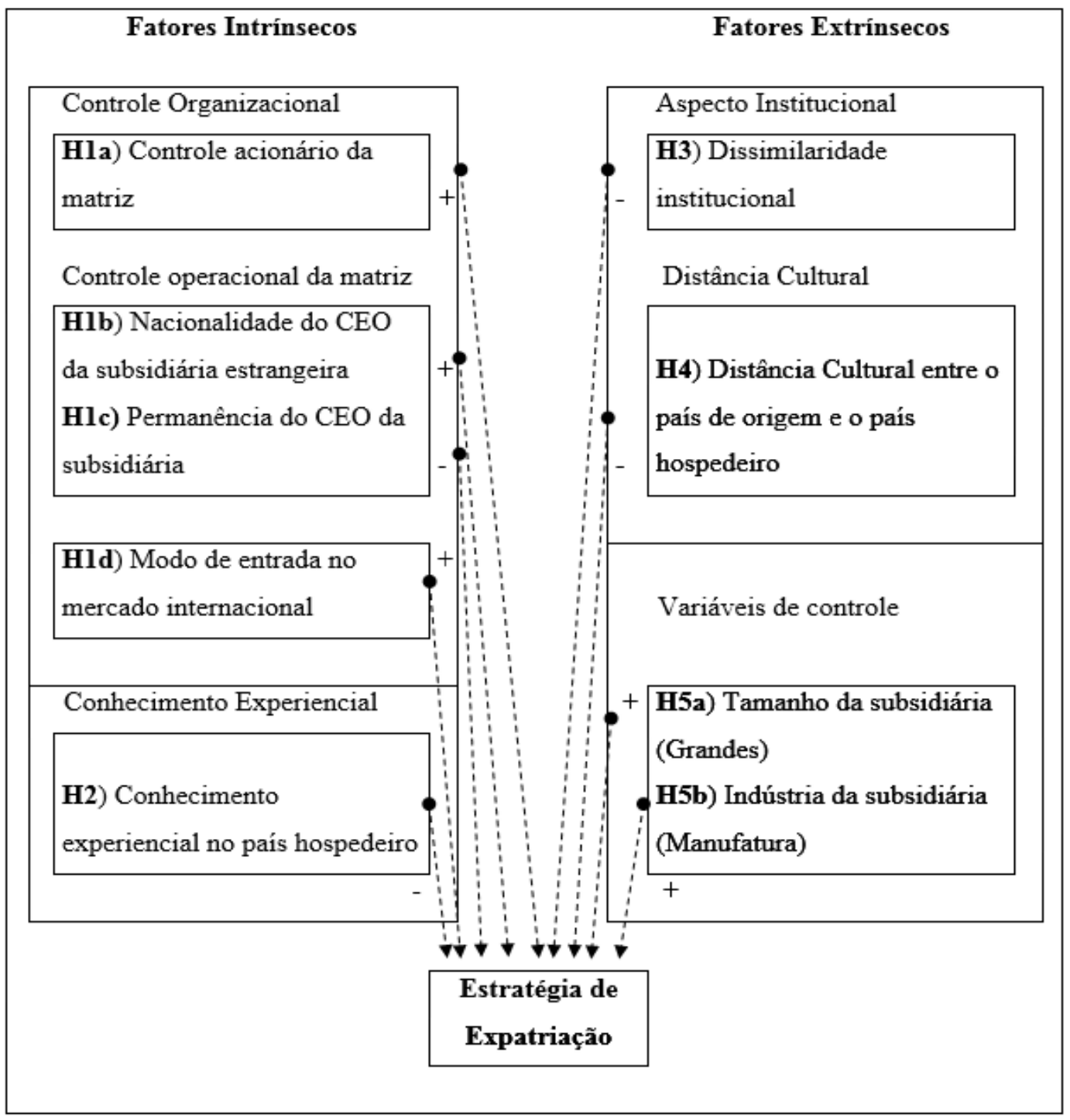

Figura 1 - Proposição do framework inicial dos fatores determinantes da estratégia de expatriação nos níveis institucional e organizacional

Fonte: Elaborada pelos autores com base nos dados da pesquisa (2014). 
As hipóteses do estudo foram elaboradas a partir de todos esses elementos, contudo, não abordando questões próprias do indivíduo. Nota-se que há controvérsias sobre a influência dessas variáveis sobre a decisão de expatriação, por isso, esses fatores foram escolhidos para análise, além das condições de acesso aos dados.

\section{MÉTODO DO ESTUDO}

Para a realização da pesquisa seguiram-se, os métodos e técnicas de pesquisa apresentados nesse tópico. Buscou-se com a utilização desses procedimentos a redução das incertezas e maior confiabilidade com os resultados a serem obtidos no estudo.

Tratou-se de estudo quantitativo com dados secundários coletados a partir dos relatórios anuais da Toyo Keizai. Esta base de dados é publicada em língua japonesa, sendo uma das poucas bases do mundo em que disponibilizam informação dos investimentos estrangeiros de EMNs no nível de subsidiária, já que a maioria dos dados existentes envolve mais no nível da empresa matriz (dados consolidados). Para os fatores extrínsecos, foram utilizadas as bases secundárias publicadas pela Heritage Foundation (Global Competitiveness Report - CGR), pelo World Bank (Worldwide Global Indicators - WGI) e pelo The Hofstede Centre.

Inicialmente coletaram-se dados de 1153 subsidiárias das empresas multinacionais japonesas instaladas na América Latina. Entretanto, com o intuito de acompanhar a estratégia de expatriação ao longo do tempo, foram consideradas apenas as subsidiárias com informação completa para todas as variáveis no período do estudo (2006-2012). Adicionalmente, foram desconsideradas as subsidiárias instaladas em paraísos fiscais. Por fim, foram analisadas 107 subsidiárias de multinacionais japonesas instaladas na América Latina no período de 2006 a 2012, que resultou um total de 749 observações.

A seguir são detalhadas as variáveis independentes bem como as variáveis de controle:

\section{Fatores Intrínsecos}

- Controle organizacional: As variáveis de controle organizacional referem-se: (i) ao controle acionário da matriz inferida por meio do nível percentual de distribuição do capital entre os acionistas; (ii) ao controle operacional da matriz obtido por meio do nome do gestor da subsidiária (nacionalidade do CEO da subsidiária estrangeira e a permanência do CEO da subsidiária); (iii) e ao modo de entrada no país hospedeiro: Joint Venture (JV) e subsidiária integral (WOS).
- Conhecimento experiencial: foi obtido por meio da idade e $\log$ da idade (número de anos da fundação da firma nos países) da subsidiária latina.

\section{Fatores Extrínsecos}

- Aspectos institucionais: Utilizaram-se os doze pilares institucionais do GCR nos anos de 2006 a 2012 e também os seis índices de governança do WGI do mesmo período.

- Distância cultural: analisada a partir dos 5 escores de Hofstede's (1980, 2001), do índice de distância cultural de Kogut e Singh (1988).

\section{Variáveis de Controle}

- Indústria: A indústria foi codificada como variável dummy com 1- para indicar manufatura e 0- para não-manufatura.

- Tamanho da subsidiária: Foi testada por meio do número total de funcionários, pelo $\log$ do número de funcionários e por uma variável dummy com a seguinte codificação: 0- para pequenas e médias empresas e 1- para grandes empresas. Para isso, utilizou-se codificação do Serviço Brasileiro de Apoio às Micro e Pequenas Empresas (SEBRAE, 2014).

Os dados em painel foram tabulados por meio de Regressão Múltipla. Para Hair et al. (2005) a análise de regressão múltipla é uma técnica estatística que pode ser usada para analisar a relação entre uma única variável dependente (critério) e várias variáveis independentes (preditoras). Trata-se de uma ferramenta analítica poderosa planejada para explorar todos os tipos de relações de dependência. Foi utilizado o pacote estatístico STATA 12 para a análise de regressão para dados em painel.

Realizou-se regressão múltipla para identificação de quais variáveis independentes poderiam ser determinantes da decisão de expatriação das EMNs japonesas e se a expatriação impacta o desempenho da subdiária estrangeira. Foram considerados três níveis de p-value para análise da significância das variáveis (Hair et al, 2005): (a) significância a $10 \%(\mathrm{p}<0.10)$; (b) significância a $5 \%$ $(\mathrm{p}<0.05)$; e (c) significância a $1 \%(\mathrm{p}<0.01)$.

Dentre os testes realizados com os dados em painel estão o teste de Hausman e o teste de Heteroscedasticidade. O teste de Hausman deve ser realizado para se decidir entre a utilização de dados em painel por meio da Técnica de Efeitos Fixos ou de Efeitos Aleatórios. Esse teste basicamente avalia se a heterogeneidade não observada das unidades crosssection são correlacionados com os regressores, sob a hipótese nula de que não são (GREENE, 2008).

$\mathrm{O}$ modelo de Efeitos Fixos permite que os efeitos das entidades não observadas sejam correlacionadas com as variáveis que foram incluídas no modelo (GREENE, 2008). O termo "efeitos fixos" decorre do fato de que, embora o intercepto possa diferir entre indivíduos, cada intercepto individual não 
Fatores Extrínsecos e Intrínsecos da Estratégia de Expatriação - uma Proposta de Framework para as Subsidiárias Estrangeiras

se altera ao longo do tempo, isto é, é invariante no tempo (GUJARATI, 2006).

Em contrapartida, se os efeitos entre as entidades não estiverem correlacionadas com os regressores, então é indicado utilizar-se o modelo de Efeitos Aleatórios (GREENE, 2008). Nesse sentido, primeiro realizou-se regressão com dados em painel com a técnica de Efeitos Fixos, depois regressão das mesmas variáveis com dados em painel com a técnica de Efeitos Aleatórios. Para decidir entre Efeitos Fixos ou Aleatórios, realizou-se o Teste de Hausman.

Nos dados em painel realiza-se também o Teste de Heterocedasticidade. Esse teste se faz necessário, pois ele permite identificar a presença de heterocedasticidade e restaurar o modelo de dados em painel com controle para a heterocedasticidade. Ao se constatar a existência de heteroscedasticidade entre as entidades (subsidiárias japonesas na América Latina), foi necessário fazer correção dos dados.

Em uma base de dados para estudo longitudinal, o grupo de observações pertence às mesmas entidades pode apresentar algum efeito latente que ficará acumulado por todo o período analisado, por isso, se faz necessário aplicar uma correção nos dados que indicarem presença de heterocedasticidade. Para isso, foi realizado o ajuste por meio do Estimador Robusto (GREENE, 2008).

Esse método foi utilizado na presente pesquisa, pois em todos os testes verificou-se presença de heterocedasticidade. Os modelos de regressão apresentados no tópico referente às análises dos resultados foram ajustados com a aplicação do Estimador Robusto que apresenta correções para autocorrelação e heterocedasticidade.

\section{RESULTADOS DA PESQUISA}

Os resultados da regressão múltipla entre as variáveis intrínsecas e extrínsecas e as variáveis de controle do estudo e o framework final da estratégia de expatriação são apresentados a seguir.

\subsection{Regressão múltipla entre expatriação e fatores intrínsecos}

O modelo de regressão entre expatriação (quantidade de expatriados) e as variáveis independentes e as discussões explicativas do modelo estão demonstrados a seguir. A tabela 1 apresenta o modelo de regressão com a correção de heterocedasticidade dos dados, o qual tornou o modelo estatístico confiável.

Com a realização do Teste de Heterocedasticidade foi obtido p-valor de 0,0000 . Como o p-valor foi inferior a 0,05 , rejeitou-se $\mathrm{H}_{0}$ que indica presença de homocedasticidade. Após a correção dos efeitos da heterocedasticidade sobre os dados, definiu-se o modelo de regressão da pesquisa.

A Tabela 1 demonstra os indicadores obtidos por meio da regressão múltipla entre a variável dependente "Quantidade de expatriados" e as demais variáveis independentes do estudo e representa o modelo de regressão da pesquisa para o teste das hipóteses propostas no estudo. Com relação ao controle acionário, que se refere à participação acionária do capital estrangeiro na subsidiária, o resultado mostrou uma relação negativa com expatriação, ou seja, quanto menor a participação acionária, maior é a quantidade de expatriados para a subsidiária estrangeira. Entretanto, esta relação não é estatisticamente significativa $(\mathrm{p}>0,10)$.

Tabela 1 - Resultados do modelo estimado por FGLS (VD=Quantidade de expatriados)

\begin{tabular}{|c|c|c|c|c|c|}
\hline & VARIÁVEIS & COEFICIENTE & ERRO PADRÃO & $T-V A L U E$ & $P-V A L U E$ \\
\hline \multirow{8}{*}{ 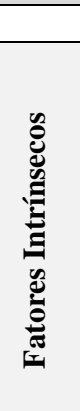 } & Constante & $7.311 * * *$ & 2.617 & 2.790 & 0.005 \\
\hline & \multicolumn{5}{|c|}{ Controle Organizacional } \\
\hline & Participação acionária & -0.818 & 1.206 & -0.680 & 0.497 \\
\hline & Modo de entrada & 0.419 & 0.320 & 1.310 & 0.191 \\
\hline & CEO japonês & $1.400 * * *$ & 0.287 & 4.870 & $\mathbf{0 . 0 0 0}$ \\
\hline & Permanência do CEO & $-0.286 * *$ & 0.146 & -1.960 & 0.050 \\
\hline & \multicolumn{5}{|c|}{ Conhecimento Experiencial } \\
\hline & Idade da subsidiária & -0.019 & 0.012 & -1.510 & 0.130 \\
\hline \multirow{5}{*}{ 党 } & Distância Cultural & & & & \\
\hline & Cultura (5 dimensões) & $-1.177 * * *$ & 0.393 & -2.990 & 0.003 \\
\hline & \multicolumn{5}{|c|}{ Aspectos Institucionais } \\
\hline & Accountability & -0.994 & 0.746 & -1.330 & 0.183 \\
\hline & Regulatório & $1.560 *$ & 0.846 & 1.840 & 0.065 \\
\hline
\end{tabular}


Fatores Extrínsecos e Intrínsecos da Estratégia de Expatriação - uma Proposta de Framework para as Subsidiárias Estrangeiras

\begin{tabular}{|c|c|c|c|c|c|}
\hline & Controle da corrupção & -0.470 & 0.954 & -0.490 & 0.623 \\
\hline & Infraestrutura & -0.558 & 0.428 & -1.300 & 0.192 \\
\hline & Bem estar populacional & 0.327 & 0.392 & 0.830 & 0.405 \\
\hline & Eficiência do mercado de trabalho & -1.096 & 0.928 & -1.180 & 0.238 \\
\hline & $\begin{array}{c}\text { Desenvolvimento do mercado } \\
\text { financeiro }\end{array}$ & 0.880 & 0.789 & 1.110 & 0.265 \\
\hline & Preparo tecnológico & 0.407 & 0.419 & 0.970 & 0.332 \\
\hline & Competitividade & $-0.618 * *$ & 0.279 & -2.210 & 0.027 \\
\hline & Operação dos negócios & $-1.45 \mathrm{E}-06^{*}$ & 8.56E-07 & -1.690 & 0.090 \\
\hline \multirow{4}{*}{$\begin{array}{l}\frac{0}{0} \\
\stackrel{0}{0} \\
\tilde{\Xi}\end{array}$} & \multicolumn{5}{|c|}{ Variáveis de controle } \\
\hline & Indústria & $1.940 * *$ & 0.885 & 2.190 & 0.028 \\
\hline & Tamanho & $1.192 * * *$ & 0.423 & 2.820 & 0.005 \\
\hline & $\begin{array}{l}\text { Núm Observ. = } 749 \\
\text { Núm.Grupos }=107 \\
\text { Obs por Grupo = } 7\end{array}$ & \multicolumn{2}{|c|}{$\begin{array}{c}\text { R-sq within }=\mathbf{0 . 0 5 1 2} \\
\text { R-sq between }=\mathbf{0 . 1 8 0 8} \\
\text { R-sq overall }=\mathbf{0 . 1 7 0 2}\end{array}$} & \multicolumn{2}{|c|}{$\begin{array}{c}\text { Wald chi2 }(18)=54.91 \\
\text { Prob }>\text { chi } 2=0.0000\end{array}$} \\
\hline
\end{tabular}

Fonte: Elaborada pela autora com base nos dados da pesquisa (2014).

Nota: FGLS = Estimador de mínimos quadrados generalizados factível; VD = Variável Dependente; * significância ao nível de $10 \%$; ** significância ao nível de 5\%; *** significância ao nível de $1 \%$.

Uma possível explicação para esta insignificância pode estar relacionada ao contexto em que foi investigado (América Latina), onde em alguns países exigem uma participação maior de capital local ao invés de estrangeiro, enquanto em outros países não existe esta exigência. Também pode estar relacionada ao setor em que a empresa multinacional investe no país estrangeiro. Devido a este resultado não significativo entre expatriação e controle acionário da empresa matriz sobre a subsidiária latina, conclui-se que a $\mathrm{H} 1 \mathrm{a}$ foi rejeitada empiricamente.

O resultado referente ao controle operacional indicou uma relação positiva e estatisticamente significativa $(\mathrm{P}<0,01)$ com expatriação, ou seja, se o CEO da subsidiária estrangeira é originário do país da empresa matriz, a empresa matriz aumenta a quantidade de expatriados para a subsidiária estrangeira, conforme tabela 1. Este resultado mostra que o papel estratégico dos expatriados relacionado ao alinhamento das operações da matriz e da subsidiária e disseminação de conhecimento entre as unidades organizacionais, como apresentado por Delios e Bjorkman (2000). Desta forma, obtém suporte empírico para a H1b.

No que se refere à permanência do CEO na gestão da subsidiária estrangeira, também se verificou pelo nome do gestor a existência ou não de rotatividade do cargo. O resultado apresentou coeficiente negativo e estatisticamente significativo $(\mathrm{p}=0,050)$, indicando a existência de uma relação inversa entre as variáveis. Desse modo, quanto menor a permanência do CEO na gestão da subsidiária estrangeira, maior a quantidade de expatriados que a matriz designa para a subsidiária. Nota-se que essa relação inversa e significativa entre as variáveis pode ser explicada pela necessidade de maior controle da empresa matriz por meio de um expatriado em momentos de incerteza como durante o período de substituição do CEO da subsidiária. Diante disso, podese dar suporte empírico a H1c.

Em se tratando do modo de entrada no mercado internacional, o resultado mostrou uma relação positiva entre o modo de entrada e expatriação, ou seja, quanto mais a empresa matriz decide entrar no país hospedeiro por meio de subsidiária integral, mais ela designa expatriados para a subsidiária estrangeira. Contudo, esta relação não é estatisticamente significativa $(\mathrm{p}>0,10)$. Desta forma, rejeita-se a H1d.

No que tange ao conhecimento experiencial o resultado da análise mostrou uma relação inversa com expatriação, ou seja, quanto maior a experiência da empresa matriz no país hospedeiro menor a quantidade de expatriados para a subsidiária estrangeira. Entretanto, esta relação não é estatisticamente significativa $(p>0,10)$. Uma possível explicação para essa insignificância pode estar relacionada aos objetivos estratégicos da empresa matriz, independentemente do conhecimento experiencial da matriz. Devido a este resultado, conclui-se que $\mathrm{H} 2$ foi rejeitada empiricamente.

\subsection{Regressão múltipla entre expatriação e fatores extrínsecos}

Os aspectos institucionais da pesquisa foram avaliados por meio dos 12 pilares do GCR e pelos seis índices do WGI. Contudo, após os testes com as variáveis dependentes e independentes só compuseram a regressão múltipla as variáveis que contribuíram para a elaboração do modelo.

Esse teste não se limitou a verificar a existência de relação direta ou inversa entre as variáveis, mas também especificar quais variáveis institucionais têm relação direta, inversa ou nenhum tipo de relação com a expatriação. 
Fatores Extrínsecos e Intrínsecos da Estratégia de Expatriação - uma Proposta de Framework para as Subsidiárias Estrangeiras

$\mathrm{Na}$ tabela 2 verificou-se que foram significantes para a decisão de expatriação as seguintes variáveis institucionais: "Aspectos regulatórios" $(\mathrm{p}<0,10)$, "Competitividade do mercado" $(p<0,05)$ e "Operações dos negócios” $(\mathrm{p}<0,10)$.

Devido a estes resultados significativos entre expatriação e dissimilaridade institucional ("Aspectos regulatórios", "Competitividade do mercado" e "Operações dos negócios") conclui-se que a H3 foi parcialmente rejeitada, dada às especificidades dos aspectos institucionais.

Em relação à Competitividade do mercado e Operações dos negócios aos Aspectos regulatórios, poderia dar suporte empírico à $\mathrm{H} 3$. Contudo, em se tratando da relação direta entre os aspectos regulatórios e expatriação, percebeu-se a necessidade de se analisar uma a uma as variáveis relacionadas aos aspectos institucionais para melhor se compreender sua influência sobre a decisão de expatriação.

A distância cultural entre os países de origem da empresa multinacional e do país hospedeiro da subsidiária estrangeira têm recebido atenção dos pesquisadores devido ao choque cultural e dificuldades de ajustamento dos expatriados em suas missões internacionais.

Na tabela 1 o resultado mostrou uma relação negativa e estatisticamente significativa $(p<0,01)$ entre distância cultural e expatriação. Ou seja, quanto maior a distância cultural entre o país de origem da matriz e o país hospedeiro da subsidiária estrangeira, menor a quantidade de expatriados para a subsidiária estrangeira.

Esse resultado corrobora com o estudo de Widmier, Brouthers e Beamish (2008), mas é contrário aos estudos de Gong (2003), Boyacigiller (1990) e Wilkinson et al (2008). Assim, obtém suporte empírico para a $\mathrm{H} 4$.

\subsection{Regressão múltipla entre expatriação e variáveis de controle}

O tamanho das subsidiárias estrangeiras seguiu classificação do SEBRAE (2014) e foi dividido em dois grupos: Pequenas e Médias empresas e Grandes empresas. A análise de regressão múltipla foi realizada separadamente com as pequenas e médias empresas que totalizaram 87 empresas e depois com as grandes empresas que totalizaram 20.

O resultado referente ao Tamanho da subsidiária (TABELA 1) mostrou uma relação positiva entre tamanho da subsidiária e expatriação. Ou seja, a designação de expatriação é influenciada pelo tamanho da subsidiária. As pequenas e médias empresas expatriam de forma diferente das grandes empresas.

Esta relação é estatisticamente relevante $(\mathrm{p}<0,01)$. Por isso, se justifica a necessidade de se fazer as análises das subsidiárias estrangeiras em separado utilizando-se a variável "Tamanho da subsidiária" como variável de controle.

Devido a este resultado significativo entre tamanho da subsidiária e expatriação, pode-se dar suporte empírico a $\mathrm{H} 5 \mathrm{a}$. Ou seja, o tamanho das subsidiárias influencia a decisão de expatriação.

Em se tratando das diferenças do setor de atuação, ou indústria, na decisão de expatriação, também foram realizadas análises em separado com os dados dos setores de manufatura, totalizando 45 empresas e não-manufatura, com um total de 62 empresas.

Devido ao resultado significativo entre expatriação e indústria $(p<0,05)$, conforme tabela 1 , obteve-se suporte empírico para a H5b. Esse resultado indica diferenças na designação de expatriação por conta das diferenças de indústria está de acordo com a pesquisa de Ando e Endo (2013), que confirmaram empiricamente uma relação direta entre as variáveis.

Após a realização dos testes de hipóteses, foram necessários ajustes no framework inicial por conta da não confirmação de algumas hipóteses. O framework final da pesquisa está disposto na Figura 2.

As implicações práticas do estudo consistiram em identificar os principais fatores intrínsecos e extrínsecos determinantes da estratégia de expatriação das empresas multinacionais. Desse modo, esse framework favorece a designação de expatriados para as subsidiárias estrangeiras, pois explica como a expatriação é realizada pelas multinacionais japonesas, que são referência mundial em expatriação. 
Fatores Extrínsecos e Intrínsecos da Estratégia de Expatriação - uma Proposta de Framework para as Subsidiárias Estrangeiras

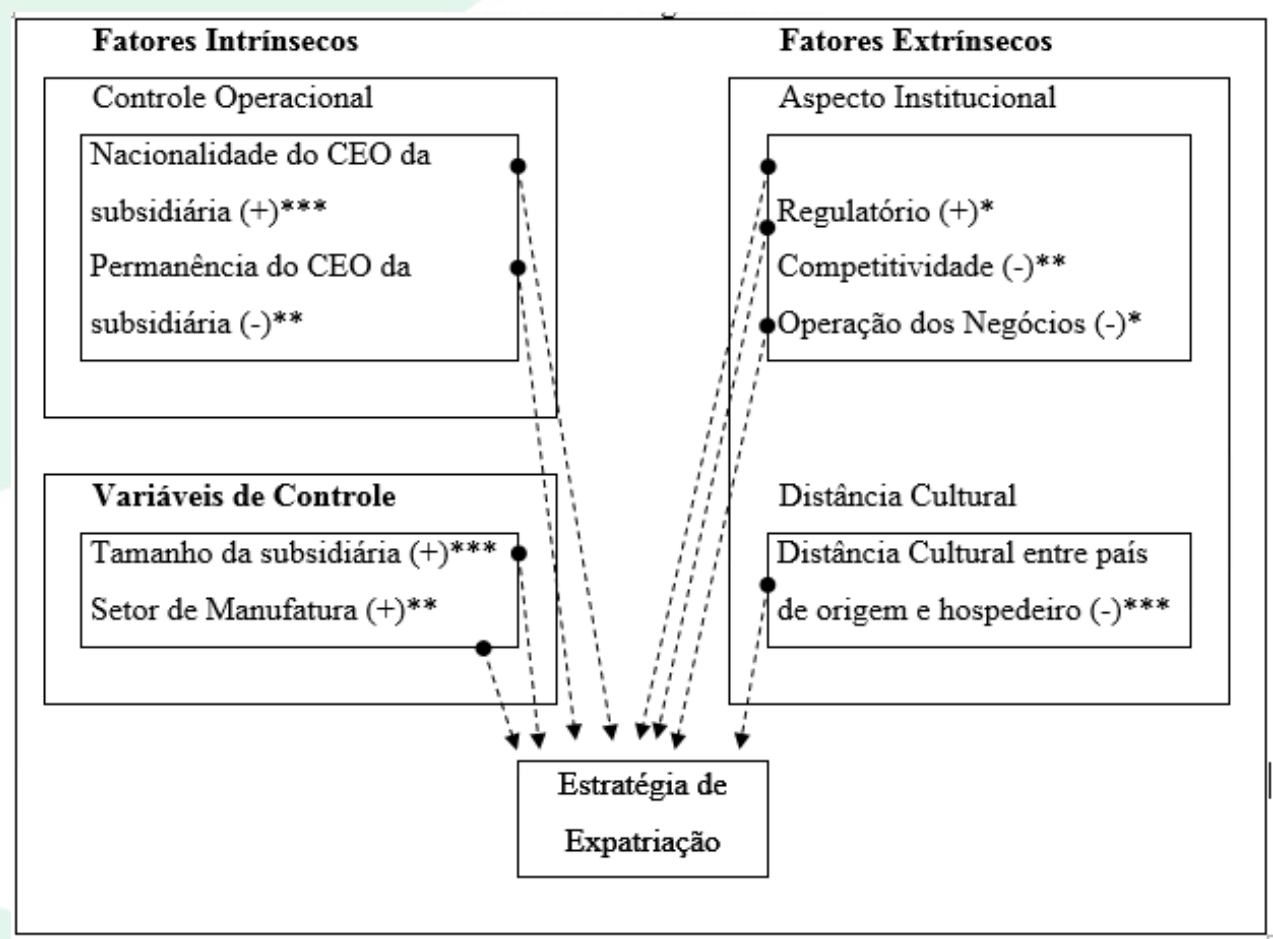

Figura 2 - Framework final dos fatores determinantes da estratégia de expatriação nos níveis institucional e organizacional

Fonte: Elaborada pela autora com base nos dados da pesquisa (2014).

Nota: $(*)$ significância a 10\% (p<0.10); $(* *)$ significância a 5\% $(\mathrm{p}<0.05) ;(* * *)$ significância a $1 \%(\mathrm{p}<0.01)$.

Consequentemente, a pesquisa pode ser utilizada como um parâmetro para as demais EMNs quando precisarem designar um gestor para suas subsidiárias estrangeiras. Não há aqui um padrão de designação de pessoal para as subsidiárias estrangeiras, mas um parâmetro para nortear as decisões das EMNs independentemente de sua nacionalidade. Compreender como a expatriação tem sido realizada pelas EMNs japonesas nas suas subsidiárias instaladas na América Latina pode ajudar outras empresas a analisarem seus próprios fatores intrínsecos e prepararem-se melhor para os desafios relacionados à expatriação.

\section{CONSIDERAÇÕES FINAIS}

A estratégia de expatriação utilizada pelas empresas multinacionais é um tema imprescindível para a eficiência das políticas de gestão internacional de recursos humanos, pois apesar de serem as pessoas que irão vivenciar as experiências, desafios e riscos nas missões internacionais, ambos (pessoas e organizações), são responsáveis e contribuem para o sucesso ou fracasso das designações internacionais.

O objetivo do estudo foi atendido, pois foram identificados os fatores intrínsecos e extrínsecos à expatriação e proposto o framework da estratégia de expatriação das empresas multinacionais. A proposição foi realizada em duas etapas: primeiro, por meio de um framework teórico inicial e, segundo, com a apresentação do framework final após os testes das hipóteses.

O problema foi respondido, pois se testou a contribuição dos fatores organizacionais (controle operacional e conhecimento experiencial) para a estratégia de expatriação das empresas multinacionais. E também a contribuição do ambiente internacional (aspectos institucionais e distância cultural) para a estratégia de expatriação das empresas multinacionais. Para isso, realizou-se teste de hipóteses com as variáveis.

Em relação ao controle organizacional, constatou-se empiricamente que a expatriação não tem uma relação direta ou inversa significativa com o controle acionário e o modo de entrada no mercado internacional. Porém, a expatriação apresentou uma relação direta e significativa com o controle operacional por meio da nacionalidade do CEO e uma relação inversa e significativa com o controle operacional por meio da permanência do CEO no cargo.

Em se tratando do conhecimento experiencial, também se constatou empiricamente que a expatriação não tem uma relação direta ou inversa significativa com o tempo de atuação da empresa no país hospedeiro.

Em relação aos aspectos institucionais, constatou-se empiricamente que a expatriação tem uma 
Fatores Extrínsecos e Intrínsecos da Estratégia de Expatriação - uma Proposta de Framework para as Subsidiárias Estrangeiras

relação direta significativa com os Aspectos regulatórios do país hospedeiro e uma relação inversa com a Competitividade do mercado e com as Operações dos negócios. Em se tratando da distância cultural constatou-se empiricamente que a expatriação tem uma relação inversa significativa com a variável. Isso implica que quanto maior a distância cultural do país de origem da matriz e o país hospedeiro da subsidiária, menos as EMNs expatriam. Por fim, no que se refere às variáveis de controle, inferiu-se a influência do tamanho da subsidiária e de seu setor de atuação nas decisões de designação internacional das EMNs.

As limitações consistiram em analisar dois dos três elementos componentes da estratégia de expatriação. A pesquisa focou em analisar os fatores determinantes da estratégia de expatriação a partir das EMNs e da influência do ambiente internacional sobre as organizações. Outra limitação foi a quantidade de missing values das variáveis e períodos considerados para o estudo.

Como estudos futuros, sugere-se a realização de uma pesquisa qualitativa com expatriados de várias nacionalidades para se compreender, na visão do indivíduo, quais os principais fatores estratégicos da expatriação de funcionários das EMNs. A compreensão de que elementos são fundamentais para a expatriação, de acordo com os anseios do próprio expatriado, comparativamente às políticas de expatriação das empresas multinacionais, proporcionaria equilíbrio entre as demandas reais do expatriado e as práticas de suporte organizacional. E também resultaria em uma pesquisa inovadora com a proposição de um framework completo da estratégia de expatriação.

Em se tratando dos aspectos institucionais, em estudos futuros poder-se-ia analisar por meio de agrupamentos como os aspectos políticos, econômicos, educacionais, de saúde e de infraestrutura, ao invés de se testar os aspectos institucionais como um todo. Também poderiam ser realizados estudos com outras formas de tratamento dos dados como aplicação de modelos de escolha discreta (MED) por ano, com dados em painel (TRAIN, 2003) e também relacionando expatriação e performance das subsidiárias estrangeiras.

\section{REFERÊNCIAS}

Abdellatif, M., Amann, B. \& Jaussaud, J. (2010). Family versus nonfamily business: a comparison of international strategies. Journal of Family Business Strategy, v. 1, p. 108-116.

Ando, N. \& Endo, N. (2013). Determinants of foreign subsidiary staffing by service firms. Management Research Review, v. 36, n.6, pp. 548-561.
Ando, N. \& Paik, Y. (2013). Localization and the performance of foreign subsidiaries. Academy of International Business, AIB 2013 Annual Meeting. Istambul, Turkey, p. 3-6, July.

Beamish, P. W. \& Inkpen, A. C. (1998). Japanese firms and the decline of the japanese expatriate. Journal of World Business, v. 33, Issue 1.

Boyacigiller, N. (1990). The role of expatriates in the management of interdependence complexity and risk in multinational corporations, Journal of International Business Studies, v. 21, n. 3, p. 357381, 1990.

Calantone, R. J. \& Zhao, Y. S. (2001). Joint ventures in China: a comparative study of Japanese, Korean, and U.S. partners. Journal of International Marketing, v. 9, n. 1, p. 1-23.

Cooke, F. L. (2012). The globalization of Chinese telecom corporations: strategy, challenges and HR implications for the MNCs and host countries. The International Journal of Human Resource Management, v. 23, n. 9, p. 1832-1852, May.

Delios, A. \& Bjorkman, I. (2000). Expatriate staffing in foreign subsidiaries of Japanese multinational corporations in the PRC and the United States. International Journal of Human Resource Management, v. 11, Issue 2, p. 278-293, Apr.

Downes, M. \& Thomas, A. S. (2000). Knowledge transfer through expatriation: the ucurve approach to overseas staffing. Journal of Managerial Issues, v. 12 , n. 2, p. 131-149.

Faro, R. \& Faro, F. (2007). Curso de Comércio Exterior - visão e experiência brasileira. São Paulo: Atlas.

Gaur, A. S., Delios, A. \& Singh, K. (2007). Institutional environments, staffing strategies and subsidiary performances. Journal of Management, v.33: pp. 611-636.

Gertsen, M. C. \& Soderberg, A. (2010). Expatriate stories about cultural encounters - a narrative approach to cultural learning processes in multinational companies. Scandinavian Journal of Management, v. 26, p. 248-257.

Geringer, J. M. \& Hebert, L. Control and performance of international joint ventures. Journal of International Business Studies, v. 20, p. 235-254, 1989. 
Gomez, C. \& Sanchez, J. I. (2005). Human resource control in MNCs: a study of the factors influencing the use of formal and informal control mechanisms. International Journal of Human Resource Management, v. 16, n. 10, Oct.

Gong, Y. (2003). Subsidiary staffing in multinational enterprises: agency, resources, and performance. Academy of Management Journal, v. 46, n. 6, p. 728-739.

Greene, W. H. (2008). Econometric Analysis. $6^{\text {th }}$ ed. Upper Saddle River, N. J.: Prentice Hall.

Grewal, R. et al. (2013). Marketing channels in foreign markets: control mechanisms and the moderating role of multinational corporation headquarterssubsidiary relationship. Journal of Marketing Research, v. 50 p. 378-398, June.

Gujarati, D. (2006). Econometria Básica. Rio de Janeiro: Elsevier.

Gupta, A. K. \& Govindarajan, V. (1991). Knowledge flows and the structure of control within multinational corporations. Academy of Management Review, v. 16, p. 768-792.

Hair Jr, J. F. et al. (2005). Análise multivariada de dados. 5. ed. Porto Alegre: Bookman.

Harvey, M. \& Novicevic, M. M. (2000). The influences of inpatriation practices on the strategic orientation of a global organization. International Journal of Management, v. 17, n. 3, p. 362-371.

Harzing, A. W. (2001). Who's in charge? An empirical study of executive staffing practices in foreign subsidiaries. Human Resource Management, v. 40, p. 139-158.

Hilmersson, M. \& Jansson, H. (2012). Reducing uncertainty in the emerging market entry process: on the relationship among international experiential knowledge, institutional distance, and uncertainty. Journal of International Marketing, v. 20, n. 4, p. 96-110.

Hofstede, G. (2001). Culture's consequence: comparing values, behaviors, institutions and organizations across nations. $2^{\text {nd }}$ ed. CA: Sage Publications.

Hofstede, G. (1980). Culture's consequences: international differences in work-related values. Beverly Hills: Sage.
Hofstede; G. \& Minkov, M. (2010). Cultures and Organizations: Software of the Mind. 3rd Edition, McGraw-Hill USA.

Hymer, S. (1960). The International Operations of National Firms: A Study of Direct Foreign Investment. Cambridge: MIT Press.

Jaussaud, J. \& Schaaper, J. (2006). Control mechanisms of their subsidiaries by multinational firms: A multidimensional perspective. Journal of International Management, v. 12, p. 23-45.

Kogut, B. \& Singh, H. (1998). The effect of national culture on the choice of entry mode. Journal of International Business Studies, v. 19, n. 3, p. 411432.

Kostova, T. \& Zaheer, S. (1999). Organizational legitimacy under conditions of complexity: the case of the multinational enterprise. Academy of Management Review, v. 24, p. 64-81.

Le, N. H. (2009). Foreign parent firm contributions, experiences, and international joint venture control and performance. International Management Review, v. 5, n. 1.

Ogasavara, M. H. (2012). Entry mode and parent control: the impact of equity ownership changes on the longevity of japanese FDI in Brazil. International Journal of Management, v. 29, n. 1, part. 1, mar.

O’Donnell, S. W. (2000). Managing foreign subsidiaries: agents of headquarters, or an interdependent network? Strategic Management Journal, v. 21, p. 525-548, May.

Paik, Y. \& Ando, N. (2011). MNC's competitive strategies, experiences, and staffing policies for foreign affiliates. The International Journal of Human Resource Management, v. 22, n. 15, p. 3003-3019, Sept.

Peng, G. Z. (2012). FDI legitimacy and MNC subsidiary control: From legitimation to competition. Journal of International Management, v. 18 , p. $115-131$.

Train, K. (2003). Discrete Choice Methods with Simulation. Cambridge University Press. Cambridge.

Schotter, A. \& Beamish, P. W. (2011). General manager staffing and performance in transitional economy subsidiaries: a subnational analysis. International Studies of Management \& Organization, v. 41, n. 2, p. 55-87, Summer. 
Fatores Extrínsecos e Intrínsecos da Estratégia de Expatriação - uma Proposta de Framework para as Subsidiárias Estrangeiras

Serviço Brasileiro de Apoio às Micro e Pequenas Empresas (2013). Disponível em: <http://www.sebrae.comm.br $>$. Acesso em: $26 \mathrm{dez}$.

Singh, D. (2012). Emerging economies and multinational corporations: An institutional approach to subsidiary management. International Journal of Emerging Markets, v. 7, n. 4, p. 397410.

Tan, D. \& Mahoney, J. T. (2006). Why a Multinational Firm Chooses Expatriates: integrating resourcebased, agency and transaction costs perspectives. Journal of Management Studies, v. 43, n. 3, May.
Widmier, S., Brouthers, L. E. \& Beamish, P. W. (2008). Expatriate or local? Predicting Japanese, subsidiary expatriate staffing strategies. The International Journal of Human Resource Management, v. 19, n. 9, p. 1607-1621, Sept.

Wilkinson, T. J. et al. (2008). The diminishing effect of cultural distance on subsidiary control. Journal of International Management, v. 14, p. 93-107.

Xu, D., Pan, Y. \& Beamish, P. W. (2004). The effect of regulative and normative distances on $\mathrm{MNE}$ ownership and expatriate strategies. Management International Review, v. 44, Issue 3, p. 285-307. 